\title{
Monobutyl phthalate induces the expression change of G-Protein-Coupled Receptor 30 in rat testicular Sertoli cells
}

\author{
Yang Hu${ }^{1,2,3}$, Dongmei Li ${ }^{1,2,3}$, Yuqiu Lu1, 2, 3, Xiaodong Han 1, 2, 3 \\ ${ }^{1}$ Immunology and Reproduction Biology Laboratory, Medical School, Nanjing University, Nanjing, \\ Jiangsu 210093, China \\ ${ }^{2}$ Jiangsu Key Laboratory of Molecular Medicine, Nanjing University, Nanjing, Jiangsu 210093, China \\ ${ }^{3}$ State Key Laboratory of Analytical Chemistry for Life Science, Nanjing University, Nanjing, Jiangsu \\ 210093, China
}

\begin{abstract}
The aim of the study was to explore whether G-Protein-Coupled Receptor 30 (GPR30) was expressed in rat testicular Sertoli cells and to assess the impact of monobutyl phthalate (MBP) on the expression of GPR30 in Sertoli cells. By using RT-PCR, Western-Blot and immunofluorescent microscopy, the expression of GPR30 in rat Sertoli cells was found at both gene and protein level. Cultures of Sertoli cells were exposed to MBP (10$-1000 \mu \mathrm{M}$ ) or a vehicle. The results indicated that the expression of GPR30 increased at gene and protein levels in Sertoli cells following administration of MBP even at a relatively low concentration. We suggest that changes of GPR30 expression may play an important role in the effects of the xenoestrogen MBP on Sertoli cell function. (Folia Histochemica et Cytobiologica 2013, Vol. 51, No. 1, 18-24)
\end{abstract}

Key words: monobutyl phthalate, GPR30, Sertoli cell, xenoestrogen, nongenomic action, rat

\section{Introduction}

Phthalates belong to chemicals widely used in industry. They include endocrine disrupting chemicals (EDCs) acting as hormone-like agents that may interfere with the synthesis, secretion, transport and elimination of natural hormones in the body [1]. $\mathrm{Di}(n-$ butyl) phthalate (DBP) is a weak estrogenic compound extensively applied in the cosmetics industry and medical products [2]. Data suggested that xenoestrogens, such as DBP, exert adverse effects on the development of male reproductive system. For example, DBP treatment in pregnant rats could cause a set of disorders in male offspring, including Leydig cell aggregation and hyperplasia, the suppression of intratesticular testosterone level, an increased number of gonocytes, and the presence of multinucleated

Correspondence address: Dongmei L., Xiaodong H. Medical School, Nanjing University, 22 Hankou Road, Nanjing, 210093, China; tel./fax: +8625836864 97; e-mail: lidm@nju.edu.cn; hanxd@nju.edu.cn gonocytes in fetal testis [3-5]. In addition, DBP exposure in utero led to hypospadias, cryptorchidism, prostate, epididymis and vas deferent agenesis, decreased anogenital distance and delayed preputial separation [6] which resemble the symptoms of testicular dysgenesis syndrome related to diminished testosterone action in the fetal period of life [7].

It was shown in previous studies that the majority of xenoestrogens exerted their estrogenic effects primarily by binding to classical estrogen receptors (ERs). However, it has been demonstrated that all the xenoestrogens possess a very weak affinity for ERs [8]. For example, DBP is approximately six to seven orders of magnitude less potent than $17 \beta$-estradiol [2]. The mechanisms by which xenoestrogens might affect the male reproductive system at a relatively low concentration remain unknown. Besides the classical genomic action, increasing evidence indicates that estrogen can also cause rapid, nongenomic action by binding to a specific membrane estrogen receptor [8]. The G-protein-coupled non-classical membrane ER (GPCR), also known as GPR30, has been widely rec- 
ognized as a membrane ER which plays an important role in nongenomic actions. It was demonstrated by many authors that binding of estrogen to GPR30 could trigger the up-regulation of intracellular $\mathrm{Ca}^{2+}$ and cAMP, and then activate the mitogen activated protein kinase (MAPK) pathway [9]. Based on similar chemical structure, xenoestrogens may also mimic such nongenomic actions of estrogens.

Monobutyl phthalate (MBP), the active monoester metabolite of DBP hydrolyzed by intestinal hydrolases upon ingestion and absorption in the gut [10, 11], could inhibit fetal testosterone synthesis, resulting in the anti-androgenic effect of DBP [12]. Additionally, MBP inhibited testicular descent in prenatal rats after administering to pregnant rats from 15 th to 17th gestational day [13]. In bovine adrenal chromaffin cells and human neuroblastoma SH-SY5Y cells, DBP and MBP suppressed the increase of the epibatidine-induced $\mathrm{Ca}^{2+}$ concentration [14]. MBP was reported to have estrogenic activity in several kinds of animals and cell types, however its mechanism of action needs to be determined.

Sertoli cells (SCs), located within the seminiferous epithelium, are involved in the formation of bloodtestis barrier. SCs exert an important function in nourishing and supporting germ cells and play an essential role in normal onset of spermatogenesis. It was reported that exposure to MBP can destroy junctional structures between Sertoli cells [15], and it has been suggested that specific impairment of Sertoli cell microenvironment can induce a dysfunction in sperm production.

The aim of our study was to investigate whether GPR30 is expressed in Sertoli cells and examine the possible effect of MBP on the expression of GPR30 in Sertoli cells in rat testis. In the current study we have demonstrated that GPR30 participated in the response of MBP-treated Sertoli cells.

\section{Material and methods}

Primary culture of rat testicular Sertoli cells. Sprague-Dawley rats were purchased from Nanjing Medical University and kept in accordance with the NIH Guide for the Care and Use of Laboratory Animals. Sertoli cells were isolated from the testes of 28-day-old rats in accordance with the method of Li with some modifications [16]. Testes were removed and decapsulated, then washed twice in phosphatebuffered saline (PBS). The seminiferous tubules were dispersed gently using ophthalmic forceps and then transferred into $50 \mathrm{~mL}$ plastic tubes. The seminiferous tubules were digested in $0.25 \%$ trypsin solution in a rocking incubator $\left(35^{\circ} \mathrm{C}\right.$, $50 \mathrm{rpm}, 7 \mathrm{~min}$ ) to remove Leydig cells and other interstitial tissue, followed by $0.1 \%$ collagenase I treatment $\left(35^{\circ} \mathrm{C}, 200\right.$ rpm, $25 \mathrm{~min}$ ) to remove the peritubular cells. The homogenate was filtered through a 100 -mesh (100 sieve meshes per square inch) stainless steel filter, and collected by centrifugation at $1200 \mathrm{rpm}$ for $7 \mathrm{~min}$. Cells were washed three times in PBS. Isolated cells were placed on cell culture dishes at a density of $1.5 \times 10^{6}$ cells $/ \mathrm{ml}$. Cells were grown initially in DMED/F-12 medium with $5 \%$ fetal bovine serum (FBS), containing sodium bicarbonate $(2.4 \mathrm{mg} / \mathrm{L})$, HEPES $(15 \mathrm{mM} / \mathrm{L})$, penicillin $(100 \mathrm{IU} / \mathrm{mL})$, and streptomycin (100 IU/mL). Cells were incubated in a humidified atmosphere of $95 \%$ air, $5 \% \mathrm{CO}_{2}$ at $35^{\circ} \mathrm{C}$. After 2 days of culture, Sertoli cells with tiny protruding dendrites were attached to the bottom of the dishes, while most of germ cells were suspended in the medium. After the medium was changed the purity of the cultured Sertoli cells was more than $95 \%$.

Reverse Transcription-PCR assay. RT-PCR assay was used to demonstrate the mRNA expression of GRP30 in Sertoli cells. By using Column Animal RNAout kit (TIANDZ, Beijing, China), total RNA was extracted from cultured Sertoli cells in vitro according to the manufacturer's protocol. Purity of the total RNA was determined by the ratio of absorbance readings at $260 \mathrm{~nm}$ and $280 \mathrm{~nm}$, the result of 260/ $1280 \mathrm{~nm}$ fell in the range of 1.8-2.0. After diluting the samples to obtain the same concentration $(0.05 \mu \mathrm{g} / \mu \mathrm{L})$, the total RNA was reverse-transcribed using the EasyScript FirstStrand cDNA Synthesis SuperMix (TranGen Biotech Co., Beijing, China). The resulting cDNA was used for PCR. The PCR master mix contained $12.5 \mu \mathrm{L} 2 \times$ Taq master mix (BOERDI, Nanjing, China), $1 \mu \mathrm{L} \mathrm{cDNA}, 1 \mu \mathrm{L}$ forward primer $(10 \mu \mathrm{M}), 1 \mu \mathrm{L}$ reverse primer $(10 \mu \mathrm{M})$ and $9.5 \mu \mathrm{L}$ nucleasefree water. Primers specific for our target genes were designed as showed in Table 1. 18S rRNA was chosen as a housekeeping gene. Compared with beta-actin and glyceraldehyde-3-phosphate dehydrogenase, $18 \mathrm{~S}$ rRNA was the most stable housekeeping gene and superior for normalization in comparative analyses [17]. Reactions were run in the following conditions: $1 \times 95^{\circ} \mathrm{C} 2 \mathrm{~min}, 27 \times\left[95^{\circ} \mathrm{C} 30 \mathrm{~s}, 56^{\circ} \mathrm{C}\right.$ $30 \mathrm{~s}$ and $\left.72^{\circ} \mathrm{C} 30 \mathrm{~s}\right]$. PCR products were separated on a $1 \%$ agarose gel, stained with ethidium bromide and viewed under a UV transilluminator (Junyi-Dongfang Co., Beijing, China)

RT-PCR was also used to observe whether MBP exposure in vitro alters the expression of GPR30 in Sertoli cells. Purified Sertoli cells were plated into 6-well culture plates at $1.5 \times 10^{5}$ cells $/ \mathrm{mL}$ in $2 \mathrm{~mL}$ culture medium. After $24 \mathrm{~h}$ incubation cells were treated with $17 \beta$-estradiol (E2) $(0.1 \mathrm{nM})$ as positive control and $\operatorname{MBP}(0,10,100,1000 \mu \mathrm{M})$, and incubated at $35^{\circ} \mathrm{C}$ for $5,10,15,30 \mathrm{~min}$ and 24 hours. GPR30 expression in the treated Sertoli cells was measured by RT-PCR assay performed as described above.

Western blotting. Cells were washed twice with cold PBS and lysed in a lysis buffer (50 mMTris- $\mathrm{HCl} \mathrm{pH} \mathrm{7.4,} 150 \mathrm{mM}$ 
Table 1. Primers used in RT-PCR experiment

\begin{tabular}{|l|c|c|c|}
\hline \multirow{2}{*}{ GENE } & \multicolumn{2}{|c|}{ Primer information } \\
\cline { 2 - 3 } & Primer & Sequence (5'-3') & \multirow{2}{*}{ Length } \\
\hline \multirow{2}{*}{ GPR30 } & Forward & GGACGAGCAGTATTACGATA \\
\cline { 2 - 3 } & Reverse & CCAGCAGATGAAGAAGACA & \multirow{2}{*}{$124 \mathrm{bp}$} \\
\cline { 2 - 3 } & Forward & TGCCTTCCTTGGATGTAG & CGTCTGCCCTATCAACTTTCG \\
\cline { 2 - 3 } & Reverse & & \\
\hline
\end{tabular}

$\mathrm{NaCl}, 1 \mathrm{mM}$ PMSF, 1 mM EDTA, $1 \%$ Triton X-100 and 0.1\% SDS) for $30 \mathrm{~min}$ on ice. The lysate was centrifuged at $12,000 \times g$ for $15 \mathrm{~min}$, the supernatants were collected and protein concentration was determined by Bradford protein assay. Proteins were separated by $12 \%$ SDS-polyacrylamide gel electrophoresis and electroblotted onto polyvinylidene fluoride (PVDF) membrane (Roche, Mannheim, Germany) by standard procedures. Transferred blots were incubated sequentially with blocking agent (5\% non-fat milk in PBS-tween), primary antiGPR30 antibodies (Abcam Co., Hong Kong, China) and peroxidase conjugated secondary antibodies (Boster Company, Wuhan, China). Signal detection was performed with an enhanced chemiluminescence detection kit. Band density was measured by Bio-Rad Quantity One software.

Immunofluorescence study. Sertoli cells cultured on polylysine-coated coverslips for $24 \mathrm{~h}$ were fixed in $4 \%$ (wt/vol) paraformaldehyde for $20 \mathrm{~min}$ and then permeabilized for 5 min with $0.25 \%$ (vol/vol) Triton X-100 at room temperature. After rinsing with PBS three times, cells were blocked with $3 \%$ bovine serum albumin for $30 \mathrm{~min}$. After washing, cells were incubated with primary anti-GPR30 antibodies (1:50 dilution) overnight at $4^{\circ} \mathrm{C}$. Alexa Fluor 594 donkey anti mouse $\operatorname{IgG}$ (Invitrogen, USA) was applied for $30 \mathrm{~min}$ at $37^{\circ} \mathrm{C}$ to visualize staining. After three times washing, cells were incubated with $1 \mu \mathrm{g} / \mathrm{mL}$ 4',6-diamidino-2-phenylindole (DAPI, Invitrogen, USA) for 5 min to stain cell nuclei. The coverslips were attached to glass slides using $90 \%$ glycerin and visualized under a confocal scanning laser microscope.

Immunofluorescence was used to evaluate whether MBP exposure in vitro alters the expression or location of GPR30 in Sertoli cells. Sertoli cells were cultured on polylysine-coated coverslips for $24 \mathrm{~h}$. Cells were treated with $\operatorname{MBP}(0,10,100$, $1000 \mu \mathrm{M}$ ) and incubated at $35^{\circ} \mathrm{C}$ for $5,15,30$ and $60 \mathrm{~min}$. After incubation, immunofluorescence was used to detect the distribution of GPR30 according to the protocol described above.

\section{Results}

\section{The expression of GPR30 in Sertoli cells}

The expression of GPR30 in Sertoli cells was demonstrated at mRNA level (Figure 1), and at protein lev-

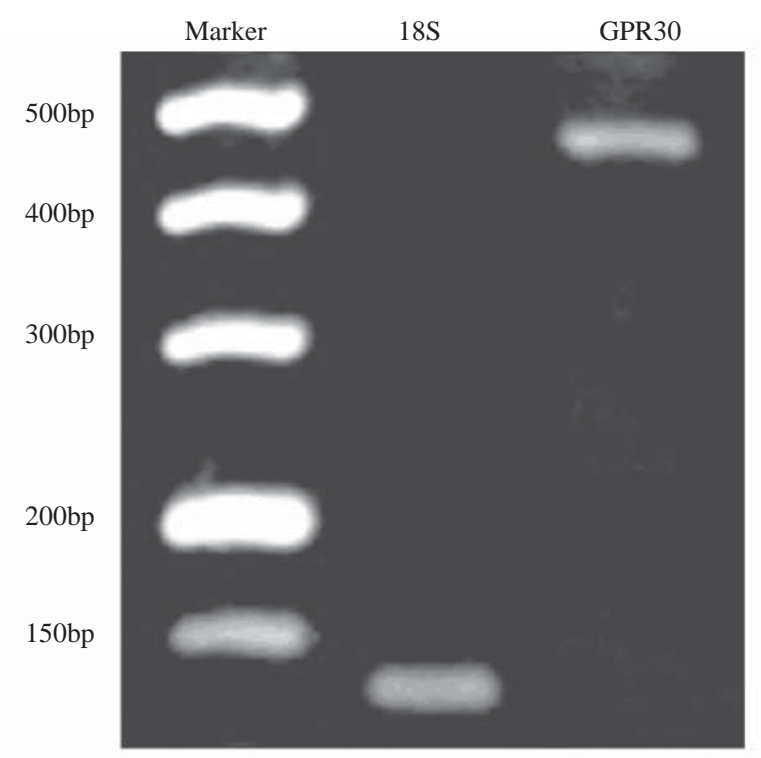

Figure 1. GPR30 mRNA expression in Sertoli cells as determined by RT-PCR. Figure shows only gel electrophoresis of the PCR products and their respective molecular weights (EtBr staining)

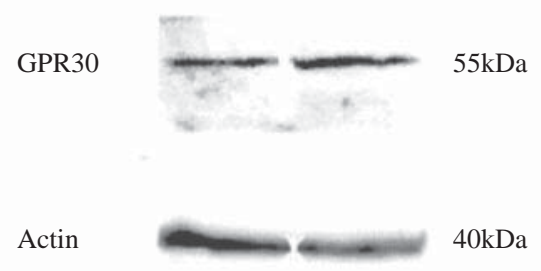

Figure 2. GPR30 protein expression in Sertoli cells as determined by Western blot method

el by immunoblotting and cell immunofluorescence analysis. Affinity-purified GPR30 antibody detected a single band with an apparent molecular weight of $55 \mathrm{kDa}$ in the immunoblot analysis (Figure 2). As shown in Figure 3, GPR30 was mainly distributed on cell membrane and not in cell nuclei. 

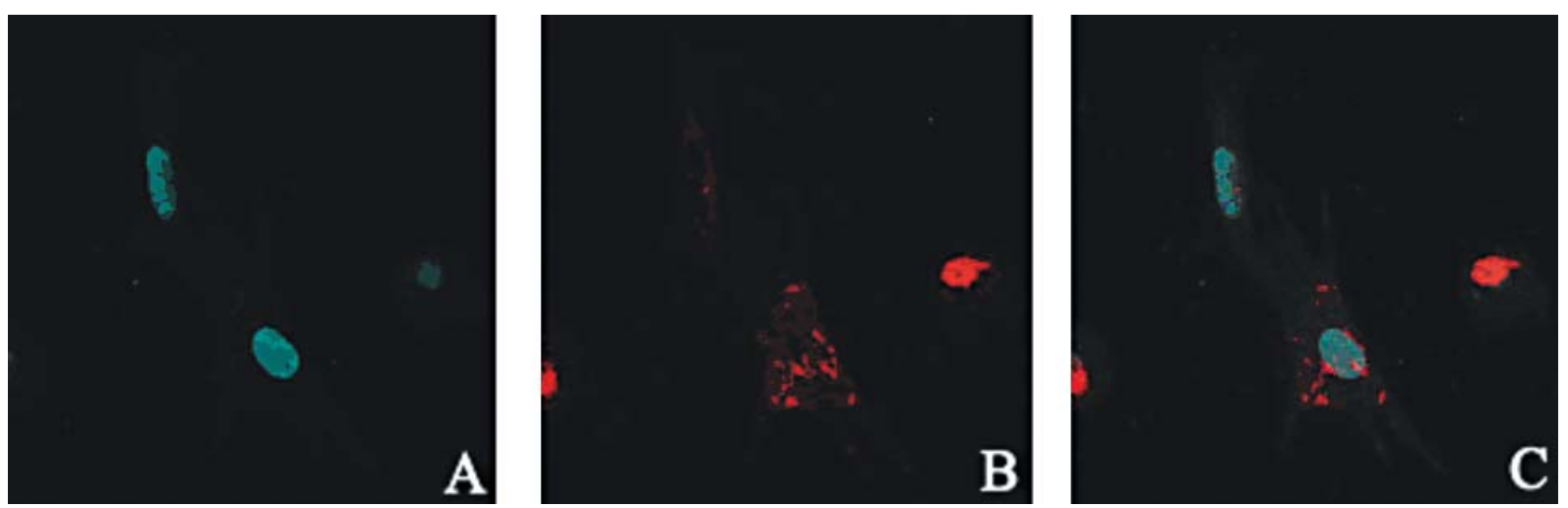

Figure 3. The distribution of GPR30 in untreated Sertoli cells. A: Nuclei of Sertoli cells were visualized by DAPI staining; B: GPR30 protein presence in Sertoli cells was detected by Alexa Fluor 594 immunofluorescence; C: merged image
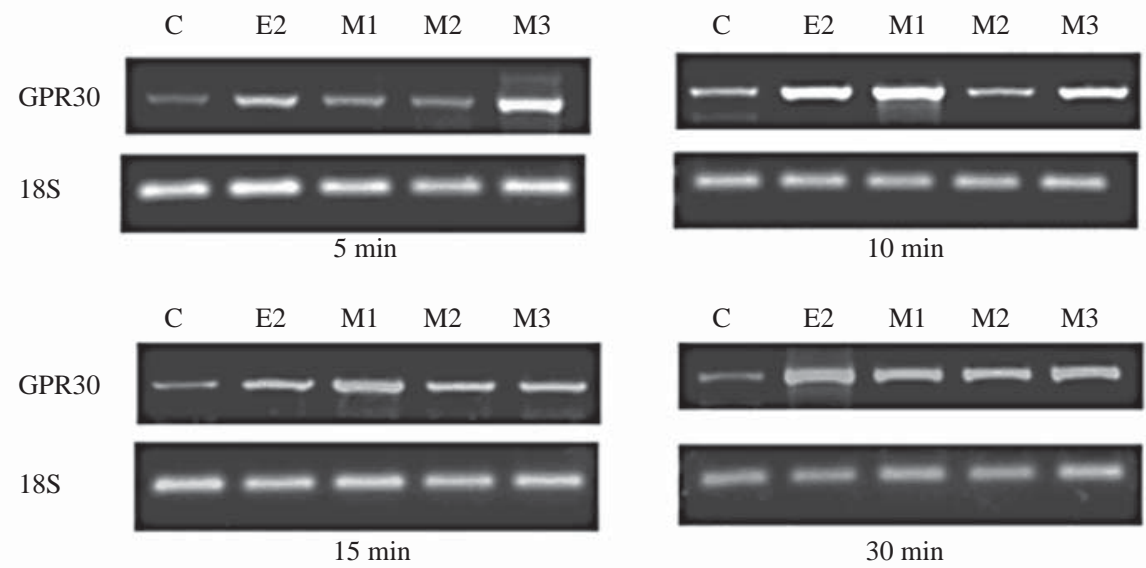

Figure 4. Effects of MBP on gene expression of GPR30 in Sertoli cells. Cells were treated with MBP at various concentrations for 5, 10, 15 and 30 min. C: control group; $\mathrm{E}_{2}: 17 \beta$-estradiol group; M1: $10 \mu \mathrm{M} \mathrm{MBP}$; $2: 100 \mu \mathrm{M} \mathrm{MBP} ; \mathrm{M} 3: 1000 \mu \mathrm{M}$ MBP. The experiments were repeated three times

\section{The effect of MBP on the expression of GPR30 in Sertoli cells}

Sertoli cells were treated with $17 \beta$-estradiol (E2) and MBP at different concentrations and collected at different time points $(5,10,15,30 \mathrm{~min}$ and $24 \mathrm{~h})$. The results are presented in Figures 4 and 5. In the positive control group (E2 group), the level of GPR30 mRNA was gradually up-regulated from 5 to $15 \mathrm{~min}$. At low $(10 \mu \mathrm{M})$ and high $(1000 \mu \mathrm{M})$ concentrations of MBP, there was a similar trend in GPR30 mRNA expression with E2 group. However, after exposure to MBP for $24 \mathrm{~h}$, the data showed a downward trend in the mRNA level of GPR30 (Figure 5). Protein distribution of GPR30 was mostly unchanged after exposure to MBP for 30 and 60 min (Figure 6).

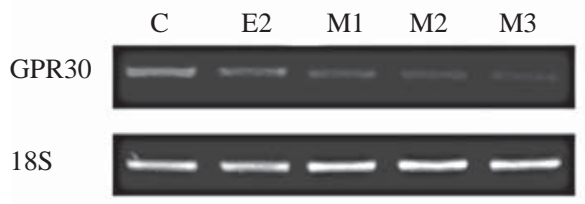

Figure 5. Effects of MBP on gene expression of GPR30 in Sertoli cells treated with MBP at various concentrations for 24 h. C: control group; $\mathrm{E}_{2}: 17 \beta$-estradiol group; M1: $10 \mu \mathrm{M}$ MBP; M2: $100 \mu \mathrm{M}$ MBP; M3: $1000 \mu \mathrm{M}$ MBP. The experiments were repeated three times

\section{Discussion}

In many animal and cell models it was shown that environmental estrogens could induce rapid, cell-sur- 

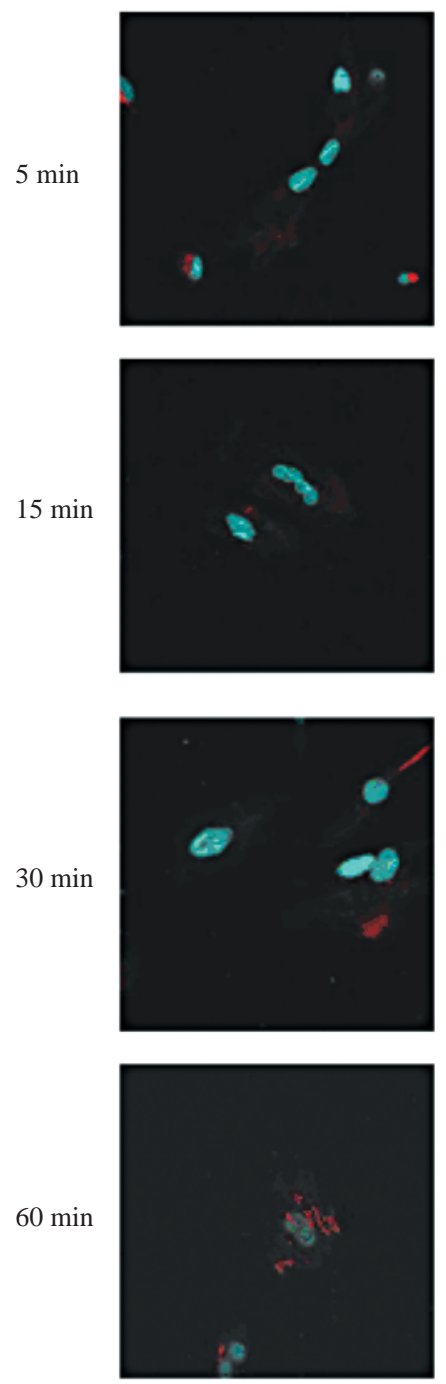

C
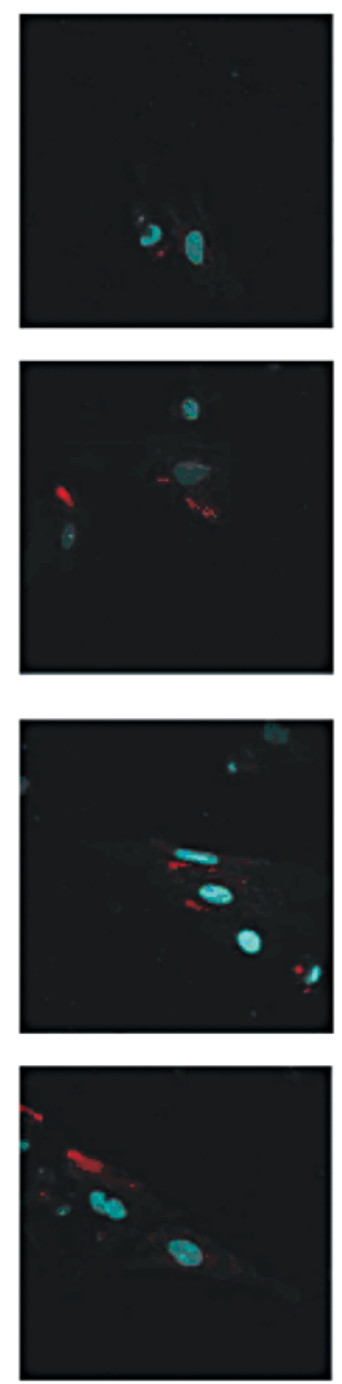

M1
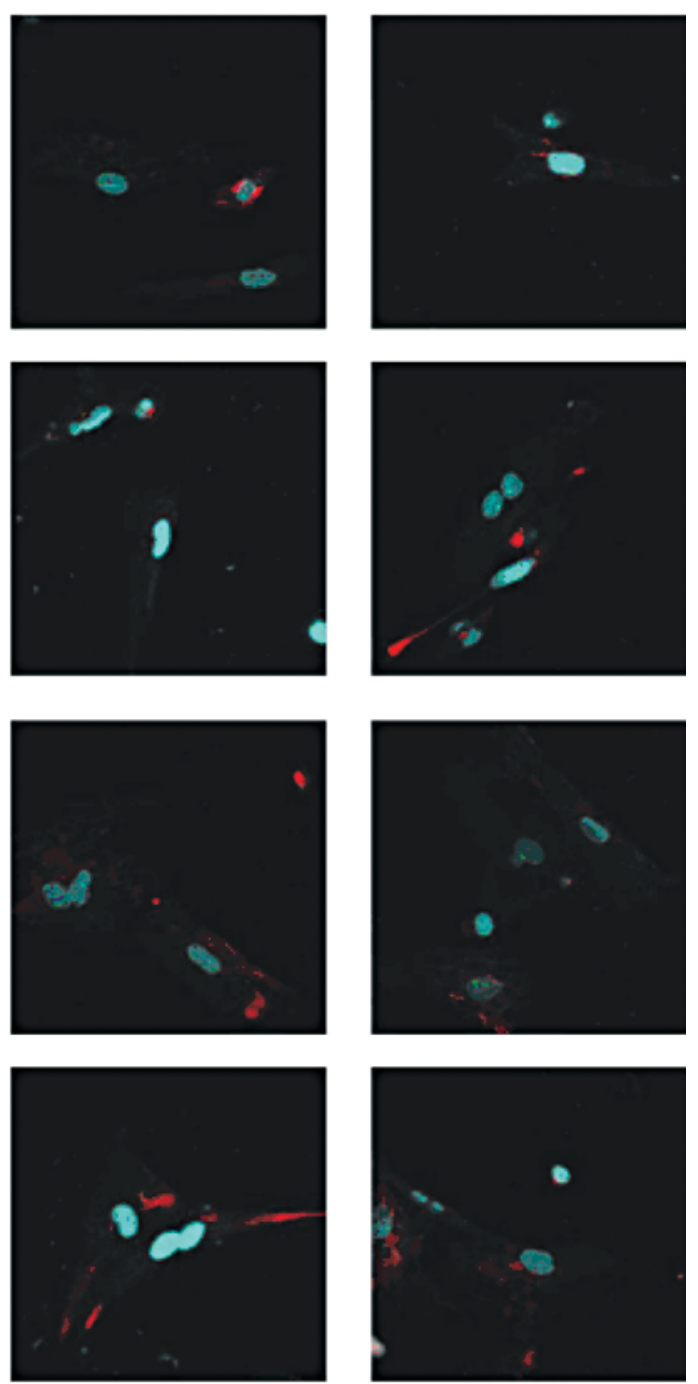

M2

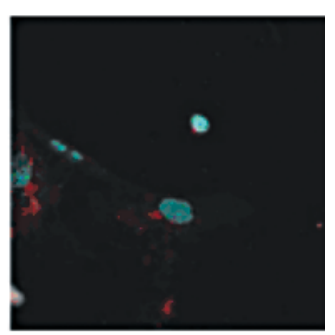

M3

Figure 6. Effects of MBP on changes in the expression of GPR30 in Sertoli cells. Cells were exposed to MBP at various concentrations for 5, 15, 30 and $60 \mathrm{~min}$. The expression of GPR30 was detected by immunofluorescence. C: control group; $\mathrm{E}_{2}: 17 \beta$-estradiol group; M1: $10 \mu \mathrm{M}$ MBP; M2: $100 \mu \mathrm{M}$ MBP; M3: $1000 \mu \mathrm{M}$

face initiated nongenomic action [18, 19]. However, there were few studies concerning whether GPR30 can be expressed in Sertoli cells and whether xenoestrogens can affect the expression of GPR30. The results of the present study provide the first clear evidence that estrogen membrane receptor GPR30 is expressed in Sertoli cells in rat testes. The treatment of Sertoli cells with MBP could up-regulate mRNA expression level of GPR30 after short exposure, however, the level was down-regulated after cell exposure to MBP for 24 hours. These results illustrate that GPR30 may be regarded as a sensitive biochemical marker for observing the rapid response of Sertoli cells to MBP.
In the present in vitro study, we focused on the effect of relatively low concentrations of MBP on GPR30 expression. The selected doses of MBP could not induce cytotoxicity to Sertoli cells. Our previous investigations had shown that $\mathrm{EC}_{50}$ of MBP for inhibiting the viability of Sertoli cells was 16mM [16], suggesting that the doses used in our study did not affect cell viability. It needs to be emphasized that the concentrations at a micro-molar level used in our study are rarely encountered in the environment, which, however, does not exclude toxicological implications of the current study. MBP is present in a variety of foods and can be accumulated to a high level in human body through food intake, while it is not easily degraded [20]. 
In our study, we speculate that GPR30 is the binding site in the plasma membrane for MBP. As a member of the rhodopsin-like family of G-protein-coupled receptors spanning the membrane seven times, GPR30 is an integral membrane protein that localizes to the endoplasmic reticulum and plasma membrane. GPR30 has a high affinity to estrogens, and their binding results in intracellular calcium mobilization and synthesis of phosphatidylinositol $(3,4,5)$ -trisphosphatein the nucleus. This protein therefore plays a role in the rapid nongenomic signaling events widely observed following stimulation of cells and tissues with estrogen-like chemicals [21, 22]. It is interesting that a wide variety of xenoestrogens with diverse structures have strong binding affinities for GPR30. For example, Bisphenol A has the binding affinity to GPR30 as much as 8-50 times higher than that to ERs. Nonylphenol and Kepone have the binding affinity for GPR30 3-4-fold higher than that for the ERs. In contrast, the binding affinity of mycotoxin for ER $\alpha$ is $8-20$-fold higher than its affinity for GPR30 [23-25]. The above data imply that GPR30 might mediate estrogen actions induced by xenoestrogens [9]. Treatment of GPR30-positive cells with estrogens could activate the intracellular signaling pathways. $17 \beta$-estradiol has been shown to activate Erk$1 / 2$ kinase via transactivation of the epidermal growth factor (EGF) receptor by the release of proHB-EGF from the cell surface [26].

In addition, xenoestrogens can activate the second messenger system by binding to GPR30 [27]. Downstream of G-protein, estrogen-like chemicals lead to activation of a SRC-like tyrosine kinase, phosphorylation of the adaptor protein SHC, and through the activation of a metalloprotease, the extracellular release of heparin-bound epidermal growth factor (HB-EGF) [9].The release of HB-EGF activates the EGF receptor resulting in the induction of the mitogen-activated protein kinase (MAPK) pathway. There can be also other pathways involved. Phosphoinositide 3-kinase (PI3K) pathway also could be activated via GPR30. As a result of the accumulation of phosphatidylinositol 3,4,5-trisphosphate (PIP3), the antiapoptotic and proliferative kinase AKT becomes activated $[28,29]$. All of these signaling events happen within seconds and minutes, furthermore, these signals elicit changes in the gene expression of a whole network of transcription factors including SRF, CREB, and members of the ETS family which promotes the expression of a second wave of transcription factors such as FOS, JUN, EGR1, ATF3, $\mathrm{C} / \mathrm{EBPd}$, and NR4A2. Cells become literally reprogrammed under the effect of this network of transcription factors [30].
Our results indicate that MBP stimulates the gene expression of GPR30 within 5-30 min, which corresponds to the effects of $17 \beta$-estradiol. We speculate that MBP caused a rapid, nongenomic effect through binding with GPR30 in the cell membrane, then converted into specific signaling pathway downstream and mediated the mRNA expression of GPR30. We suggest that after 24 hours GPR30 protein formed negative feedback to inhibit the mRNA level of GPR30 as the dose of MBP rose. The present results showed that MBP potentially interfered with the estrogen action through GPR30 in Sertoli cells. Since xenoestrogens could potentially cause estrogen-like action through GPR30 in a wide range of tissues, extensive studies on the biological function of GPR30 are needed to determine the action induced by xenoestrogens.

In summary, we showed that GPR30 was expressed in rat Sertoli cells at both gene and protein level. The exposure of Sertoli cells to MBP influenced the expression of GPR30. This might indicate that GPR30 may be a potential mediator of the action of MBP on Sertoli cells. Future studies should demonstrate whether MBP has the ability to trigger the nongenomic effects.

\section{Acknowledgment}

This work was supported by National Natural Science Foundation of China (30970530, 31200401), the National Basic Research Program of China (973 program 2010CB945103), Natural Science Foundation of Jiangsu Province of China (BK2012307), and Open Research Fund of State Key Laboratory of Bioelectronics, Southeast University.

\section{References}

1. CrispTM, Clegg ED, Cooper R, et al. Environmental endocrine disruption: An effects assessment and analysis. Envir Health Persp. 1998;106:11-56.

2. Filipiak E, Walczak-Jedrzejowska R, Krupinski M, et al. Di(n-butyl) phthalate has no effect on the rat prepubertal testis despite its estrogenic activity in vitro. Folia Histochem Cytobiol. 2011;49:685-689.

3. Mylchreest E, Sar M, Wallace DG, Foster PMD. Fetal testosterone insufficiency and abnormal proliferation of Leydig cells and gonocytes in rats exposed to di(n-butyl) phthalate. Reprod Toxicol. 2002;16:19-28.

4. Barlow NJ, PMD Foster. Pathogenesis of male reproductive tract lesions from gestation through adulthood following in utero exposure to di(n-butyl) phthalate. Toxicol Pathol. 2003;31:397-410.

5. Hallmark N, Walker M, McKinnell C, et al. Effects of monobutyl and di(n-butyl) phthalate in vitro on steroidogenesis and Leydig cell aggregation in fetal testis explants from the rat: Comparison with effects in vivo in the fetal rat and neonatal marmoset and in vitro in the human. Environ Health Persp. 2007;115:390-396. 
6. Mylchreest E, Sar M, Cattley RC, Foster PMD. Disruption of androgen-regulated male reproductive development by $\mathrm{Di}(\mathrm{n}$-butyl) phthalate during late gestation in rats is different from flutamide. Toxicol Appl Pharmacol. 1999;156:81-95.

7. Ema M, E Miyawaki, K Kawashima. Critical period for adverse effects on development of reproductive system in male offspring of rats given di-n-butyl phthalate during late pregnancy. Toxicol Lett. 2000;111:271-278.

8. Revelli A, M Massobrio, J Tesarik. Nongenomic actions of steroid hormones in reproductive tissues. Endocrine Rev. 1998;19:3-17.

9. Maggiolini M, D Picard. The unfolding stories of GPR30, a new membrane-bound estrogen receptor. J Endocrinol. 2010;204:105-114.

10. Mylchreest E, Wallace DG, Cattley RC, Foster PMD. Dosedependent alterations in androgen-regulated male reproductive development in rats exposed to di(n-butyl) phthalate during late gestation. Toxicol Sci. 2000; 55:143-151.

11. Tanaka K, Sato M, Tomita Y, Ichihara A.Biochemical studies on liver functions in primary cultured hepatocytes of adult rats.1. Hormonal effects on cell viability and proteinsynthesis J Biochem. 1978;84:937-946.

12. Parks LG,Ostby JS, Lambright CR, et al. The plasticizer diethylhexyl phthalate induces malformations by decreasing fetal testosterone synthesis during sexual differentiation in the male rat. Toxicol Sci. 2000;58:339-349.

13. Shono T,S Suita. Dose-dependent effect of phthalate ester on testicular descent in pre-and post natal rats. Urolog Res. 2003;31:293-296.

14. Liu PS, FW Tseng, JH Liu. Comparative suppression of phthalate monoesters and phthalate diesters on calcium signalling coupled to nicotinic acetylcholine receptors. J Toxicol Sci. 2009;34:255-263.

15. Schettler T. Human exposure to phthalates via consumer products. Int J Andrology. 2006;29:134-139.

16. Hu Y, DM Li, XD Han. Analysis of combined effects of nonylphenol and Monobutyl phthalate on rat Sertoli cells applying two mathematical models. Food Chem Toxicol. 2012;50:457-463.

17. Bas, A., et al., Utility of the housekeeping genes $18 \mathrm{~S}$ rRNA, beta-actin and glyceraldehyde-3-phosphate-dehydrogenase for normalization in real-time quantitative reverse transcriptase-polymerase chain reaction analysis of gene expression in human T lymphocytes. Scandinavian Journal of Immunology, 2004;59(6):566-573.

18. Loomis AK, P Thomas. Effects of estrogens and xenoestrogens on androgen production by Atlantic croaker testes in vitro: Evidence for a nongenomic action mediated by an estrogen membrane receptor. Biol Reprod. 2000;62:995-1004.

19. Nadal A, Ropero AB, Laribi O, Maillet M, Fuentes E, Soria B. Nongenomic actions of estrogens and xenoestrogens by binding at a plasma membrane receptor unrelated to estrogen receptor alpha and estrogen receptor beta.Proc Nat Acad Sci U.S.A. 2000; 97:11603-11608.

20. Frederiksen H, Aksglaede L, Sorensen K, et al. Urinary excretion of phthalate metabolites in 129 healthy Danish children and adolescents: Estimation of daily phthalate intake. Environ Res. 2011;111:656-663.

21. Manavathi, B. and R. Kumar. Steering estrogen signals from the plasma membrane to the nucleus: two sides of the coin. J Cell Physiol. 2006;207:594-604.

22. Prossnitz, ER, JB Arterburn, and LA Sklar. GPR30: A G protein-coupled receptor for estrogen. Mol Cell Endocrinol. 2007; 265-266:138-142.

23. Harris HA, Bapat AR, Gonder DS, Frail DE. The ligand binding profiles of estrogen receptors alpha and beta are species dependent. Steroids. 2002;67:379-384.

24. Hu JY, T Aizawa. Quantitative structure-activity relationships for estrogen receptor binding affinity of phenolic chemicals. Water Res. 2003; 37:1213-1222.

25. Matthews J, Celius T, Halgren R, Zacharewski T. Differential estrogen receptor binding of estrogenic substances: a species comparison. Journal of Steroid Biochem Molec Biol. 2000;74:223-234.

26. Filardo EJ, Quinn JA, Bland KI, Frackelton AR. Estrogeninduced activation of Erk-1 and Erk-2 requires the G protein-coupled receptor homolog, GPR30, and occurs via transactivation of the epidermal growth factor receptor through release of HB-EGF. Molec Endocrinol. 2000;14:1649-1660.

27. Thomas P, J Dong. Binding and activation of the seven-transmembrane estrogen receptor GPR30 by environmental estrogens: A potential novel mechanism of endocrine disruption. J Steroid Biochem Molec Biol. 2006; 102:175-179.

28. Filardo EJ, Quinn JA, Bland KI, Frackelton AR, Jr. Estrogeninduced activation of Erk-1 and Erk-2 requires the G protein-coupled receptor homolog, GPR30, and occurs via trans-activation of the epidermal growth factor receptor through release of HB-EGF. Molec Endocrinol. 2000;14:1649-1660.

29. Revankar CM, Cimino CM, Sklar LA et al. A transmembrane intracellular estrogen receptor mediates rapid cell signaling. Science. 2005;307:1625-1630.

30. Pandey, DP, Lappano R, Albanito L et al. Estrogenic GPR30 signalling induces proliferation and migration of breast cancer cells through CTGF. EMBO J. 2009;28:523-532.

Submitted: 11 July, 2012

Accepted after reviews: 27 February, 2013 